University for Business and Technology in Kosovo

UBT Knowledge Center

Nov 7th, 9:00 AM - 5:00 PM

\title{
"New" Subjects in Mechatronics Management Education
}

Peter Kopacek

Technische Universität Wien, kopacek@ihrt.tuwien.ac.at

Follow this and additional works at: https://knowledgecenter.ubt-uni.net/conference

Part of the Robotics Commons

\section{Recommended Citation}

Kopacek, Peter, "'New" Subjects in Mechatronics Management Education" (2015). UBT International Conference. 41.

https://knowledgecenter.ubt-uni.net/conference/2015/all-events/41

This Event is brought to you for free and open access by the Publication and Journals at UBT Knowledge Center. It has been accepted for inclusion in UBT International Conference by an authorized administrator of UBT Knowledge Center. For more information, please contact knowledge.center@ubt-uni.net. 


\title{
"New" Subjects in Mechatronics Management Education
}

\author{
Peter Kopacek
}

Vienna University of Technology, Institute for Mechanics and Mechatronics, IHRT

Favoritenstrasse 9-11/E325 A6, A - 1040 Wien

kopacek@ihrt.tuwien.ac.at

\begin{abstract}
Process - and manufacturing automation as well as robotics are currently one of the fast growing fields in automation. Advanced process control, cyber-physical systems, industry 4.0 and "advanced robots" are no longer a headline. They are in realization. As a consequence of these developments new social, ethical and human questions appear.

Therefore this contribution is a first report about the continuous "modernization" of the Mechatronics Management BSc and MSc programs which are successful running at UBT. Both programs were developed in the framework of two TEMPUS projects from an international consortium from 2006 to 2009. Since that time new "buzzwords" appears. For a contemporary education of the participants these new subjects have to be included in the curricula.
\end{abstract}

Keywords: Process Automation, Manufacturing Automation, Robots, Social aspects, Ethics.

\section{Introduction}

We are currently in the "Third Industrial Revolution - the Information Age". This requires highly flexible enterprises with the three headlines:

Cooperation,

Globalization,

Information.

Therefore modern enterprises have to be:

- $\quad$ Forced to have a strategic ability to create and select opportunities.

- Able to combine global strategies with local implementation.

- Able to work processes leveraged across business.

- $\quad$ Able to rapidly deploy functional skills doing the work which best exploits the business opportunities.

This requires not only new operations strategies, new technologies, but also worker involvement, environmental issues, ethical issues.....

Technology is a set of processes, tools, methods and equipment used to produce goods and services. Technology is the application of knowledge to solve human problems. 


\section{Mechatronics}

In many engineering areas a lot of changes are taking place nowadays. The classical methods and working ways of mechanical engineering are changing rapidly. To be able to cope with the multiple futures' challenges, the traditional engineering working ways need to be replaced before entering the new technological area. This process is called mechatronics which is the technology that assemble together the traditional disciplines of mechanical engineering, electronics and data processing. Almost everyone is faced with this combination of mechanical engineering, electronic and electrical engineering in our daily life. We all know Discman or a Minidisk; they consist of both mechanical and electrical parts: a motor" mechanical" to turn the disc and a pickup that reads the music "electromechanical". Furthermore, the products are loaded with electronics, of which the most advanced components include microprocessors to reduce noise and adjust for movement.

Therefore Mechatronics consists of the integration of mechanical engineering with electronics, computer systems, and advanced controls to design, construct, and operate products and processes. Mechatronics is one of the newest branches of engineering with far-reaching applications. Generally, a mechatronic system can be seen as a mechanism, which is driven by actuators that are controlled via microelectronics and software using feedback from one or more sensors. Mechatronics is therefore the title given to the sub-discipline of engineering which studies the integration of mechanical and electronic technologies to create 'intelligent' machines, systems and controllers.

\section{Mechatronics \& Mechatronics Management Education}

Up to now, conventional engineering education throughout Europe, has been dominated by technical subjects, and had little to offer in terms of interdisciplinary academic training. Topics relating to economics, business management and jurisprudence have ty pically been addressed through short 'onthe-job' courses as part of ongoing professional development within the workplace, rather than as compulsory subjects within the context of third or fourth level engineering programmes. On the other hand, graduates from business schools, for example, have rarely had the chance to extend their knowledge in technical fields again developing these skills through ongoing (and typically short) professional development programmes organised through work or some professional body .

\section{A Mechatronics Management Programme}

A number of well-educated economically-disadvantaged so-called "second" and "third" world societies have recognised the potential of developing a knowledge economy from a low level of development. It is readily apparent that similar opportunities exist for Kosovo, once socio-economic and political stability has been achieved (Hajrizi, Kopacek, 2014).

All this suggested the need for a new type of degree programme, requiring a non-traditional approach to curriculum development in engineering and advanced technology. This in turn implied the need for a new approach to the development of higher education inter-disciplinary programmes, especially in advanced engineering.

Therefore the main goals were:

- develop and widen their knowledge base in mechatronics engineering to Masters level standard,

- develop generic problem solving skills applicable to current, mainstream mechatronic engineering systems,

- achieve more in-depth expertise in selected areas of mechatronic engineering,

- engage in the planning, execution and written/oral presentation of an extended, industrially research orientated project.

- produce Master level engineering graduates who are able to participate effectively in a wide variety of industrial and/or research environments in the field of mechatronic engineering.

The main goal of the above design was to develop a curricula which would enable a mechatronics graduate to be conversant with business issues, and appreciate these in the context of the implementation of mechatronics technologies. 
The MSc curriculum has the following structure:

Engineering Core

Decision Analysis

Advanced Technology

Research Methods

Mathematical Modelling for Mechatronics Management

Sy stems Engineering

End of Life Management

\section{Management Core}

Advanced Management Information Systems

Leadership and Organizational Culture

Advanced Operation and Project Management

Marketing Management

\section{Major Mechatronics}

Advanced Production Technologies \& Robotics

Components of Mechatronic Sy stems

Design \& Control of Mechatronic Systems

Micro-, Nano-, Femto-, (Ato)mechatronics

Ethics

Applied Mechatronics Project

Laboratory Project

Electives

Master Thesis

Furthermore, ethics was included as a mandatory subject for the curriculum (Kopacek and Hersh, 2015). Very few engineering and technology undergraduate programmes in the western hemisphere incorporate ethics as a major subject so that this is a relatively new approach.

\section{Some Examples}

In the following some selected examples will be shortly described and discussed. 


\subsection{Production Automation}

This yields, in the past, to the development of Computer Integrated Manufacturing (CIM), Intelligent Manufacturing Systems (ims), Agile Manufacturing Systems (AMS). At that time the hard- and software possibilities were very limited and therefore industrial applications of AMS not economic. Agile manufacturing sy stems are now realized based on Cyberphy sical sy stems (CPS). CPS comprise smart machines, storage systems and production facilities capable of autonomously exchanging information, triggering actions and controlling each other independently. Based on the new Internet protocol IPv62 introduced in 2012 sufficient addresses are available to enable universal direct networking of smart objects via the Internet. Now is possible to network resources, information, objects and people to create the "Internet of Things and Services" (Fig. 1).

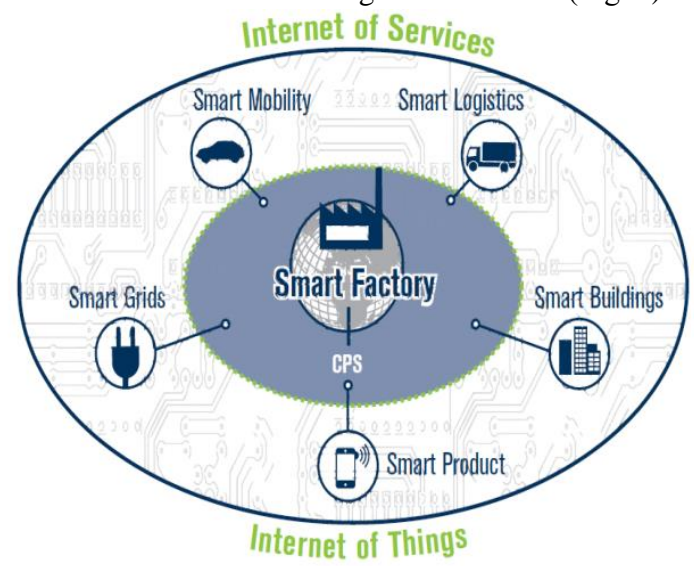

Fig. 1 The "Internet of Things" (acatech, 2013)

The effects of this phenomenon will also be felt by industry like under the headline "Industry 4.0".The basic principle of Industry 4.0 is that by connecting machines, work pieces and systems, it 's possible to create intelligent networks along the entire value chain that can control each other autonomously. Some examples for Industry 4.0 are machines that predict failures and trigger maintenance processes autonomously or self-organized logistics that react to unexpected changes in the production.

Industry 4.0 will involve the technical integration of CPS into manufacturing and logistics and the use of the Internet of Things and Services in industrial processes.

Further development trends could be:

Environmentally Conscious Manufacturing. Efficient use of materials and natural resources in production, Minimize the negative consequences on the environment (green manufacturing, cleaner production and sustainable manufacturing).

Design for environment (DFE). Select materials that require minimum energy to produce, select processes that minimize waste of materials and energy, design parts that can be recycled or reused, design products that can be readily disassembled to recover the parts, design products that minimize the use of hazardous and toxic materials, give attention to how the product will be disposed of at the end of its useful life.

Smart Factories Beginning to appear and employ a completely new approach to production. Such factories allow to fulfill individual customer requirements. Because of their flexibility last-minute changes in production are possible.

Smart products are uniquely identifiable, may be easily located at all times, know their own history, current status, alternative routes to achieving their target state.

\subsection{Renewable Energies}

- Wind power

- Hydropower

- Solar Energy

- Biomass 
- Biofuel

- Geothermal Energy

These main renewable energies could be divided in three main groups:

Controllable:

Biomass, Biofuel

Partially controllable:

Hydropower, Geothermal Energy

Uncontrollable:

Wind power and Solar Energy.

Especially Wind power and Solar Energy are depending from the weather and are therefore completely uncontrollable.

\subsection{Smart Grids}

A Smart Grid is an energy network that integrates the consumption and feed-in patterns of all market participants connected to it. It ensures an economically efficient, sustainable supply system with low losses and high availability. To manage the energy transition, it is essential to keep distribution networks efficiently in balance by means of sensor, management and control systems depending on the relevant requirements.

Until now the generation of electric power was concentrated at few power plants. From these power plants the energy was distributed to the consumers. The control of such a network was reasonable easy because it was a "one way" system. With the development of renewable energies especially photovoltaics each consumer is now in the position to produce usually a small amount of electric energy mostly for the own consumption.

The remaining energy could be stored in the net. An example is shown in Fig.2

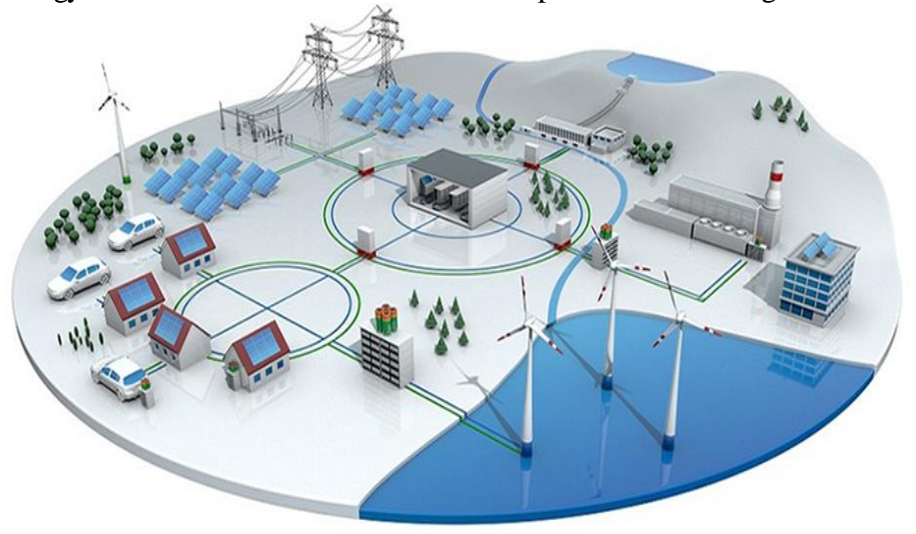

Fig. 2 Smart grid (acatech, 2013).

We have central power plants (water, goal, gas, ....) but also photovoltaic plants and houses with photovoltaic cells which are storing energy in the net. Therefore the control of such a net is much more complicated and currently only partially solved. Futhermore we have, as pointed out in 5.2 wind, geothermal energy.

\subsection{Autonomous driving cars}

It's an old dream of humans to have a car with the ability to program the goal of a travel and your car will go autonomously there. Currently we are on the way to make this dream true.

For this it is necessary that the car is able to found the optimal way under the restrictions of traffic rules, traffic jams, construction areas, The next step is to follow this path optimal. For these tasks the following key technologies are necessary: 
- Stereo video cameras for recognize objects e.g. road signs, lane markers,......

- Short and long range radar sensors for object detection.

- Side laser scanners.

- Ultrasonic sensors.

- Differential GPS for map creation.'

According to the currently available technologies the realization is very expensive and in addition the roads have to be prepared for this technology.

But there will be some advantages:

- Less traffic accidents

- Reduction of fluel consumption until $20 \%$

- Additional time for managers.

One of the main disadvantages is the loss of experience of the drivers to drive the car manually. Probably they have to prove that the car was driven for a distinct time in a distinct time interval. This is obligatory for the operators of the Vienna Underground.

\section{Summary}

OUR "PHILOSOPHY” FOR TEACHING THESE SUBJECTS

One of the main goals of our engineering and mechatronics management education consists to give our participants an overview and especially an idea about the "vocabulary" of the specialists in these distinct subjects. Furthermore the students have to be informed about the newest developments in technology, economics, .... regardless when they will be realized in industry. Because of these goals most of the courses must be "reengineered" every y ear.

Because usual control engineering as well as mechanics will be presented in a very mathematical sense we prefer an "industrial" approach with examples from the industry without any mathematical ballast. This approach requires from the lecturers a lot of preparation time and a really good industrial background. According to our experiences it is very difficult to find appropriate lecturers for these topics.

Some of our headlines for teaching these new subjects are

- Technical problems have technical solutions.

- Engineering is not only computing.

- Ensure an understandable good basic education (mathematics, physics ...).

- Try to include as early as possible technical subjects in curricula's

- Try to make the curricula's more flexible.

- "High tech" requires knowledge in English language.

- Modern technical education has to be interdisciplinary

- Laboratory equipment for "High tech" is absolutely necessary but usually very expensive. donations from companies - manpower for operation and maintenance.

\section{References}

1. German Academy of Science and Engineering - acatech (2013): Securing the future of German manufacturing industry. Recommendations for implementing the strategic initiative INDUSTRIE 4.0. Final report of the Industrie 4.0 Working Group. Acatech 2013.

2. Hajrizi, E. and Kopacek, P. (2014); Engineering Management in Kosovo. Proceedings of the 19th IFAC World Congress. The International Federation of Automatic Control, Cape Town, South Africa. August 24-29, 2014, p.9875-9879. DOI 10.3182/20140824-6-ZA-1003.01241.

3. Kopacek, P., Hersh, M. (2015): Roboethics. Ethical Engineering for International Development and Environmental Sustainability, Springer London 2015, p. 65 - 102, DOI 10.1007/978-1-4471-6618-4. 